\title{
Early termination of breast-feeding in periurban Santo Domingo, Dominican Republic: mothers' community perceptions and personal practices
}

\author{
John D. McLennan ${ }^{1}$
}

ABSTRACT Objectives. The objectives of this study were to determine: 1) whether mothers' perceptions of typical community practice for breast-feeding duration influence their personal practices and 2) whether the mothers' reports of community reasons for terminating breast-feeding identify barriers not elicited through self-report.

Methods. The study was conducted in 1997 in a sample of poor neighborhoods in a periurban district of Santo Domingo, the capital of the Dominican Republic. A representative sample of 220 mothers from these neighborhoods was interviewed with a structured questionnaire. Results. While the duration of breast-feeding was similar for self-report and for mothers' perceptions of typical community practice, there was no statistically significant correlation between these two variables. "Mother-driven" reasons for early termination of breast-feeding, such as "fear of loss of figure or of breast shape" and "not wanting to breast-feed," were frequently perceived as community reasons but rarely given as personal reasons. Personal reasons were predominately "child-driven," including "the child not wanting the breast," or reasons beyond the mother's control such as having "insufficient" milk.

Conclusions. Maternal report of community reasons for early termination may be a useful way to identify factors that would not otherwise be revealed on self-report. These additional reasons may guide health promotion efforts aimed at increasing breast-feeding duration.

Key words Breast-feeding, surveys, research methodology, maternal and child health, Dominican Republic.

Along with many other countries in Latin America, the Dominican Republic is reported to have a pattern of early termination of breast-feeding (1-2). This is a concern since shorter

\footnotetext{
McMaster University, Canadian Centre for Studies of Children at Risk, Hamilton, Ontario, Canada. Send correspondence to: John McLennan, Canadian Centre for Studies of Children at Risk, McMaster University, Patterson Building, 2nd Floor, 1200 Main Street W., Hamilton, Ontario, Canada L8N-3Z5. Telephone: (905) 521-2100, ext. 74176; fax: (905) 574-6665; e-mail: mclennjd@mcmaster.ca
}

periods of breast-feeding are associated with increased morbidity and mortality in young children, particularly in poor communities (3-4). Multiple studies have identified various reasons for early termination; Scott and Binns (5) provide a review of the literature. Nevertheless, most studies rely on maternal self-report to determine reasons for early termination of breastfeeding, or the studies restrict their analysis to various sociodemographic or behavioral variables such as the mother's age or the age of the child at introduction of bottle feeding. Such approaches may limit the identification of important factors that may influence the duration of breast-feeding and thus limit the identification of potential targets for interventions.

Having the mother report on her perception of her community's practice is a complementary approach that may identify additional factors. Utilizing the mother as a community informant might generate a broader or dif- 
ferent range of responses than might be the case if a mother only reported on her own experience. Such questioning would allow the mother's response to be based on all her experiences with other women in the community. Such questioning may also identify reasons that are less socially acceptable and hence less likely to be elicited on selfreport.

A second reason for this research approach would be to investigate whether perceptions of community practice influence a mother's own practice. According to Ajzen's theory of planned behavior (6), such influence could occur through an impact on "normative beliefs" (the perceived behavioral expectations of others); those beliefs in turn contribute to "subjective norms" (the perceived social pressure to engage in behavior). For some behaviors, such as adolescent substance abuse, the perception of others' practices has been found to be a more powerful predictor of personal use than actual community practice (7). However, whether perception of community practices on breast-feeding is associated with actual practice is unknown.

This study utilized data from a community study to determine the duration of breast-feeding and the reasons behind early termination, as reported by mothers about their personal experience and about their perception of their community's practice. It was hypothesized that duration of breast-feeding would be influenced by perception of the community's practice and that maternal reports on others would reveal additional reasons for early termination of breast-feeding not available through self-report alone.

\section{MATERIALS AND METHODS}

\section{Setting}

The study site was Los Alcarrizos, a predominantly poor periurban district of Santo Domingo, the capital of the Dominican Republic. Six poor barrios (neighborhoods) were chosen from this district. These barrios were chosen for two reasons: 1) a local child malnu- trition clinic frequently receives referrals from these neighborhoods and 2) local health promotion groups have chosen these barrios for health education interventions. Choosing neighborhoods targeted for intervention increases the possibility that the study could have input into health education efforts. These barrios were fairly new communities, having been established between 2 and 10 years before the time of the study, which was carried out in 1997. The neighborhoods had been settled predominantly by squatters.

\section{Sample}

In each of the chosen neighborhoods, every tenth house along each road and path was visited. If a child 5 years of age or younger lived in the home and a primary caretaker of that child was available, that caretaker was invited to participate in the study interview. The interview covered a variety of topics related to diarrhea prevention and hygiene, with breast-feeding questions interspersed throughout the interview schedule.

If a primary caretaker was not initially available or there was no one home, the house was visited up to two further times in an attempt to obtain an interview. This sampling process resulted in visits to 353 houses. Of these, 82 did not have any children under the age of 5 years, and 3 houses were visited repeatedly but no one was encountered. Of the remaining 268 households that were eligible for the interview, 2 declined to participate, leaving 266 households (99.3\% of the total eligible) that completed the interview. If the mother in the household had more than one child 5 years of age or younger there in the home, one child was randomly identified as the "index" child for the personal breast-feeding questions asked in the interview.

From these 266 participating households, in 220 of them $(82.7 \%)$ the person completing the interview was the mother of the index child. We restricted the breast-feeding analyses to this group of women. The caretaker non-mothers who were interviewed but excluded from our breast-feeding analyses were primarily grandmothers. Information on the full set of respondents-mothers and non-mothers-has been previously reported, along with data on other health practices covered in the interview, including the caregivers' use of purified drinking water with their children (8).

\section{Procedure}

The entire study was approved by the staff at the Children's Project/ Health Center Clinic in Los Alcarrizos and by the Institutional Review Board committee at the University of Pittsburgh. Written informed consent was obtained from all participants. All questions were asked and recorded in the child's home by two Dominican female research assistants who had previous community health and survey interview experience as well as some university education.

\section{Breast-feeding interview questions}

The research assistants utilized a structured interview to obtain the data on breast-feeding. Questions for the interview were specifically written for this study, with input from Dominican health workers. With the interview questions concerning breast-feeding, the mother was initially asked about her specific breast-feeding experience. Those not presently breast-feeding the index child were asked when and why they had stopped breast-feeding that child. Mothers were subsequently asked to give their opinion on typical practices in their community, with questions that included "Until what age do you think the mothers in the community breast-feed?" and "What are the most common reasons that mothers do not breast-feed their children for 1 year or more?" (The period of 1 year or more was chosen based on local health promotion messages and on recommendations from the World Health Organization (9)). For both personal and community-perception reasons for 
breast-feeding termination, mothers were first given an opportunity to provide as many spontaneous reasons as they wished and were then asked if there were any other reasons until they provided no further responses.

\section{Analysis}

Data analyses included Spearman correlation, chi-square $\left(\chi^{2}\right)$ analysis with continuity correction, and paired $t$ test. The analyses were performed using SAS System version 6.12 software (SAS Institute, Cary, North Carolina, United States of America).

\section{RESULTS}

The 220 mothers who completed the interviews had a mean age of 26.4 years (standard deviation (SD), 6.7 years) and 6.1 years of education (SD, 3.7 years). They had a mean of 3.5 children (SD, 2.3 children), with the index child having a mean age of 27.9 months (SD, 18.5 months). Ninetyseven percent of mothers indicated that they initiated breast-feeding when the index child was a baby. Twentythree percent of the mothers (51 of them) were still breast-feeding the index child at the time of the interview.

All the mothers reported on their duration of breast-feeding with the index child, if they had terminated breastfeeding with that child. However, only 181 of the 220 mothers $(82.3 \%)$ provided a response to the question on duration of typical community practice. Nonresponse to this question appeared to be a function of some mothers being reluctant to guess at a value for the community. Table 1 shows the results for the personal duration and for the mothers' perception of typical community duration practice.

The values are similar for self-report and for perception of community practice (Table 1). Despite there being similar values in these two categories, the Spearman correlation analysis showed no relationship between personal duration of breast-feeding and perceived community duration for the 137 women

TABLE 1. Duration of breast-feeding according to mothers' personal reports on themselves and their perception of community practices, Dominican Republic, $1997^{\mathrm{a}}$

\begin{tabular}{lccccc}
\hline & $\begin{array}{c}\text { Mean } \\
(\mathrm{mo})\end{array}$ & $\begin{array}{c}\text { Standard } \\
\text { deviation } \\
(\mathrm{mo})\end{array}$ & $\begin{array}{c}\text { Median } \\
(\mathrm{mo})\end{array}$ & $\begin{array}{c}\text { Mode } \\
(\mathrm{mo})\end{array}$ & $\begin{array}{c}\text { Range } \\
(\mathrm{mo})\end{array}$ \\
\hline $\begin{array}{l}\text { Personal duration } \\
\text { Perceived duration of } \\
\text { typical community practice }\end{array}$ & 10.2 & 8.2 & 8 & 12 & $0-36$ \\
\hline
\end{tabular}

a Information on personal duration is from 169 mothers who had terminated breast-feeding prior to the study; information on perceived duration of typical community practice is based on replies from the 181 of the 220 of the participants (82.3\%) who responded to this question.

${ }^{b}$ There was no statistically significant difference between the mean duration of personal breast-feeding and that of community perception for the 137 women who had terminated breast-feeding and who also responded to the community-perception question $(t=-1.12$, degrees of freedom $=136, P=0.27)$.

who had terminated breast-feeding and who also responded to the community duration question (Spearman correlation $r=-0.06, P=0.490)$. There was also no relationship found when the values were dichotomized to less than 12 months versus 12 months and greater $\left(\chi^{2}=1.36, P=0.243\right)$.

Both categories had very large modes at 12 months (41 women for personal duration; 84 women for perception of community duration). These modal frequencies may be inflated given a likely pattern of rounding to the nearest year by some mothers. Not captured in Table 1 is that $26 \%$ of those no longer breast-feeding had terminated before the child reached 3 months of age. This is in contrast to only $7.7 \%$ perceiving the community value to be 3 months or less.

The most common reasons that mothers gave for themselves personally terminating breast-feeding were that the "child did not want it," that the mother was pregnant with her next child, and she had "no" or "insufficient" milk (Table 2). Similar results were found for the subgroup that had breast-fed for less than 1 year, except that pregnancy was a much less common reason.

In terms of perceptions of community reasons for terminating breastfeeding before 1 year, the most common reason given was "no" or "insufficient" milk (Table 2), which was also a personal reason that many mothers reported for themselves. In contrast, the next most common rea- sons perceived for the community were not so highly rated as personal reasons. These included the mother being concerned about "loss of her figure" or "loss of breast shape" (pérdida de la figura or caída de los senos), the mother "not eating well," the mother "not wanting to," and the mother "having to work." A similar distribution of community reasons was found when just considering the subsample of early terminators, that is, those terminating breast-feeding before the child reached 1 year of age.

\section{DISCUSSION}

In terms of duration of breast-feeding, the values found were similar for the mothers' self-report and for their perception of community practice. Despite this similarity, this study found no statistical correlation between these two values. Nevertheless, in looking at reasons behind early termination of breast-feeding, the study did find that having the mothers provide their perceptions of community practice generated important additional data concerning barriers to prolonged breast-feeding that were not revealed through self-report alone.

The lack of relationship between perceived community practice and personal practice is consistent with results of research on the duration of use of purified drinking water for children in this same study (8). The age at which drinking water was no longer 
TABLE 2. Reasons for breast-feeding termination according to mothers' personal reports on themselves and their perception of community practices, Dominican Republic, $1997^{\mathrm{a}}$

\begin{tabular}{|c|c|c|c|c|c|c|c|c|}
\hline \multirow[b]{3}{*}{ Reason } & \multicolumn{4}{|c|}{ Personal reason } & \multicolumn{4}{|c|}{ Perceived community reason } \\
\hline & \multicolumn{2}{|c|}{$\begin{array}{c}\text { All } \\
\text { terminators } \\
\text { (163 mothers) }\end{array}$} & \multicolumn{2}{|c|}{$\begin{array}{l}\text { Breast-fed } \\
<1 \text { yearc } \\
(87 \text { mothers })\end{array}$} & \multicolumn{2}{|c|}{$\begin{array}{c}\text { Full } \\
\text { sample }^{d} \\
\text { (206 mothers) }\end{array}$} & \multicolumn{2}{|c|}{$\begin{array}{l}\text { Breast-fed } \\
<1 \text { year } \\
\text { (86 mothers) }\end{array}$} \\
\hline & No. & $\%$ & No. & $\%$ & No. & $\%$ & No. & $\%$ \\
\hline Child did not want it & 53 & 32.5 & 42 & 48.3 & 19 & 9.2 & 9 & 10.5 \\
\hline Pregnancy & 28 & 17.2 & 7 & 8.0 & 15 & 7.3 & 6 & 7.0 \\
\hline No or insufficient milk & 23 & 14.1 & 20 & 23.0 & 77 & 37.4 & 37 & 43.0 \\
\hline Needed weaning & 21 & 12.9 & 2 & 2.3 & 7 & 3.4 & 4 & 4.7 \\
\hline Separated from child & 21 & 12.9 & 10 & 11.5 & 59 & 28.6 & 29 & 33.7 \\
\hline Mother sick & 9 & 5.5 & 6 & 6.9 & 14 & 6.8 & 10 & 11.6 \\
\hline Mother working & 8 & 4.9 & 3 & 3.4 & 46 & 22.3 & 18 & 20.9 \\
\hline Other & 4 & 2.5 & 1 & 1.1 & 4 & 1.9 & 2 & 2.3 \\
\hline Damage to the mother & 14 & 8.6 & 3 & 3.4 & 20 & 9.7 & 8 & 9.3 \\
\hline \multicolumn{9}{|l|}{ Mother didn't want to } \\
\hline breast-feed & 4 & 2.5 & 1 & 1.1 & 50 & 24.3 & 21 & 24.4 \\
\hline \multicolumn{9}{|l|}{ Concerned about loss of figure } \\
\hline or breast shape & 0 & 0.0 & 0 & 0.0 & 69 & 33.5 & 25 & 29.1 \\
\hline Mother not eating well & 0 & 0.0 & 0 & 0.0 & 53 & 25.7 & 24 & 27.9 \\
\hline Miscellaneous & 9 & 5.5 & 6 & 6.9 & 33 & 16.0 & 11 & 12.8 \\
\hline
\end{tabular}

a Mothers could give more than one answer; total samples vary slightly due to some missing data.

${ }^{\mathrm{b}}$ All terminators $=$ those who terminated breast-feeding prior to the interview.

${ }^{c}$ Breast-fed $<1$ year $=$ all those who terminated breast-feeding prior to the interview and before the index child was one year of age.

${ }^{d}$ Full sample = all mothers, including those who were still breast-feeding.

purified for the index child was not associated with the caretakers' perception of community practice.

Nevertheless, further investigation of perceptions of community practice on breast-feeding may be warranted. First, it might be useful to look at the impact of the perceived practice of different persons within the mothers' social networks (10). Perhaps duration of breast-feeding practiced by close family members or friends would have a greater likelihood of influencing mothers' practices than would perceived community practice. Secondly, it might be useful to look at the expectation of others as opposed to the perceived practice of others in order to better tap the concept of "subjective norms" (6).

The self-report reasons for termination of breast-feeding in this study are consistent with common reasons found in a previous study in this same district (11) and in studies of other populations (12-14). In contrast, some of the perceived community reasons in this study have been much less frequently reported. In addition, the fre- quency of different reasons is very discrepant between self-report and community perception in this study.

The concern over the loss of one's figure or breast shape was one of the most discrepant findings in this study. This reason has previously been proposed as a factor that may influence the initiation of breast-feeding (10, 5-17). However, the reason does not appear to have been reported in the literature as a possible factor influencing the duration of breast-feeding. This is in spite of the fact that it is a familiar issue for those working in the field. Also not evident in the literature is the actual impact of breast-feeding on breast shape. Breast-feeding is not listed as a common cause of breast ptosis (18); rather, breast ptosis may primarily be a function of the effects of pregnancy (19).

In cases where the termination-reason frequency was high for community perception but low for personal report, such discrepancies were often for termination reasons that might be considered less socially acceptable, especially in an environment where breast-feeding is heavily promoted as being critical for healthy child development. Perhaps the implication is that mothers ought to have a "good reason" not to provide prolonged breast-feeding since they are placing their children at risk by early termination. It has been reported that some mothers may feel pressure or a sense of guilt when deciding not to breast-feed (20-21). In such an environment, it may be less acceptable for mothers to make decisions based on personal reasons (e.g., "concern about figure," "not wanting to breast-feed") than on "childdriven" reasons (e.g., "he/she no longer wanted the breast") or on barriers beyond a mother's control such as having "insufficient" milk. Consistent with this pattern is that one of the most highly discrepant findings in the other direction-that is, with the reasons given much more frequently as a personal one than as a community-perceived onewas the "child did not want the breast." The high frequency of this "childdriven" reason may be partially a function of its social acceptability. 
The reported frequency of the "mother working outside of the home" as a reason for early termination of breast-feeding was also discrepant between the community and personal report. However, this may be partially explained by the sampling procedure, which would have missed some working mothers. Support for this as a factor for influencing the discrepancy was found in the response pattern of the non-mother caretakers interviewed for those mothers who were not available for the study interview. Twenty percent of the 45 nonmothers believed that work was a personal reason for mothers' termination of breast-feeding. This value is close to the $22.3 \%$ of mothers reporting this as a perceived community reason (Table 2). This may grow as an important personal and community-perception reason given that "free trade zone" factories are located close to these communities and that young women form a substantial fraction of the labor force for such factories.

How might these results inform interventions aimed at improving breastfeeding duration? First, there is a need to consider the most common responses for breast-feeding termination, i.e., "no or insufficient milk" for the community reason and "child not wanting it" for the personal reason. Unfortunately, factors contributing to these problems were not explored further in this study. Factors may include faulty positioning or technique, inaccurate perceptions about adequacy of breast milk, and impact of early supplementary feeding. If these factors turn out to be significant contributors to shortened breast-feeding duration, then education and support programs could be directed towards them.

Second, there may be a need to address the frequent report of "motherbased" reasons for early termination. Certainly, further study is warranted to better determine the extent of influence of these reasons. One possibility would be to modify health promotion messages to stress breast-feeding benefits for the mother (22).

Finally, other interventions may need to be considered to address less frequently reported difficulties. In order to decrease the negative impact of increased work demands on mothers outside of the home, it may be necessary to increase the opportunities for breastfeeding in the workplace. In addition, improved availability of family planning services may be required in order to decrease the role of pregnancy in the early termination of breast-feeding.

Acknowledgements. This study was funded through a faculty research grant from the Center for Latin American Studies, University of Pittsburgh, Pittsburgh, Pennsylvania, United States of America.

\section{REFERENCES}

1. Bautista L. Duration of maternal breast-feeding in the Dominican Republic. Rev Panam Salud Publica 1997;1(2):104-111.

2. Perez-Escamilla R. Breast-feeding patterns in nine Latin American and Caribbean countries. Bull Pan Am Health Organ 1993;27(1):32-42.

3. Thaver I, Ebrahim G, Richardson R. Infant mortality and undernutrition in the squatter settlements of Karachi. J Trop Pediatr 1990; 36(3):135-140.

4. Mølbak K, Gottschau A, Aaby P, Hojlyng N, Ingholt L, da-Silva A. Prolonged breast feeding, diarrhoeal disease, and survival of children in Guinea-Bissau. BMJ 1994;308(6941): 1403-1406.

5. Scott J, Binns C. Factors associated with the initiation and duration of breastfeeding: a review of the literature. Breastfeed Rev 1999; 7(1):5-16.

6. Ajzen I. The theory of planned behavior. Organizational Behavior and Human Decision Processes 1991;50:179-211.

7. Iannotti R, Bush P. Perceived vs. actual friends' use of alcohol, cigarettes, marijuana, and cocaine: which has the most influence? Journal of Youth and Adolescence 1992;21: 375-389.

8. McLennan J. To boil or not: drinking water for children in a periurban barrio. Soc Sci Med 2000;51(8):1211-1220.
9. World Health Organization. Guidelines for training community health workers in nutrition. 2nd ed. Geneva: WHO; 1986.

10. Bryant $C$. The impact of kin, friend and neighbor networks on infant feeding practices: Cuban, Puerto Rican and Anglo families in Florida. Soc Sci Med 1982;16(20):1757-1765.

11. McLennan J, Spady D. Infant feeding practices in a poor district in Santo Domingo. Ecology of Food and Nutrition 1994;32:167-179.

12. Jakobsen M, Sodemann M, Mølbak K, Aaby P. Reason for termination of breastfeeding and the length of breastfeeding. Int J Epidemiol 1996;25(1):115-121.

13. Guerrero M, Morrow R, Calva J, OrtegaGallegos H, Weller S, Ruiz-Palacios G, et al. Rapid ethnographic assessment of breastfeeding practices in periurban Mexico City. Bull World Health Organ 1999;77(4):323-330.

14. Martines J, Ashworth A, Kirkwood B. Breastfeeding among the urban poor in southern Brazil: reasons for termination in the first 6 months of life. Bull World Health Organ 1989; 67(2):151-161.

15. Hull V, Thapa S, Pratomo H. Breast-feeding in the modern health sector in Indonesia: the mother's perspective. Soc Sci Med 1990;30(5): 625-633.

16. Barnes J, Stein A, Smith T, Pollock J. Extreme attitudes to body shape, social and psycholog- ical factors and reluctance to breast feed. ALSPAC Study Team: Avon Longitudinal Study of Pregnancy and Childhood. J R Soc Med 1997;90(10):551-559.

17. Foster S, Slade P, Wilson K. Body image, maternal fetal attachment, and breast-feeding. J Psychosom Res 1996;41(2):181-184.

18. Regnault P. Breast ptosis: definition and treatment. Clin Plast Surg 1976;3(2):193-203.

19. Lawers J, Woessner C. Counseling the nursing mother: a reference handbook for health care providers and lay counselors. 2nd ed. Garden City Park, New York, United States of America: Avery Publishing Group Inc; 1990.

20. Vogel A, Mitchell E. The establishment and duration of breastfeeding. Part 2: community influences. Breastfeed Rev 1998;6(1):11-16.

21. Kocturk T. Advantages of breastfeeding according to Turkish mothers living in Istanbul and Stockholm. Soc Sci Med 1988;27(4): 405-410.

22. Guttman N, Zimmerman D. Low-income mothers' views on breastfeeding. Soc Sci Med 2000;50(10):1457-1473.

Manuscript received 31 January 2001. Revised version accepted for publication on 4 May 2001. 
RESUMEN Objetivos. Los objetivos de este estudio consistieron en determinar: 1) si las percepciones de las madres acerca de las prácticas de lactancia materna típicas de su comunidad influyen sobre sus prácticas personales, y 2) si las respuestas de las madres sobre los motivos que llevan a interrumpir la lactancia materna en su comunidad identifican problemas no reflejados en las respuestas sobre sus propias prácticas.

Métodos. El estudio se realizó en 1997 en una muestra de barrios pobres de un distrito periurbano de Santo Domingo, la capital de la República Dominicana. Se utilizó un cuestionario estructurado para entrevistar a una muestra representativa de estos barrios, formada por 220 madres.

Resultados. Aunque la duración de la lactancia materna fue similar en las respuestas sobre las prácticas personales y sobre las prácticas de la comunidad, estas dos variables no estaban correlacionadas entre sí de forma estadísticamente significativa. Las razones "relacionadas con la madre" para interrumpir precozmente la lactancia, tales como el "temor a perder la figura o a la caída de los senos" y el "no querer dar de mamar", aparecieron frecuentemente como motivos en la comunidad, pero no como motivos personales. Los motivos personales fueron principalmente los "relacionados con el niño", como "el niño no quiere el pecho", o razones fuera del control de la madre, como el tener "insuficiente" leche.

Conclusiones. Los motivos identificados por la madre como causas de interrupción precoz de la lactancia materna en su comunidad pueden constituir una forma útil de identificar factores que habitualmente no se revelan en los cuestionarios sobre las prácticas personales. Estos motivos adicionales pueden ser útiles para guiar los esfuerzos de promoción de la salud destinados a aumentar la duración de la lactancia materna.

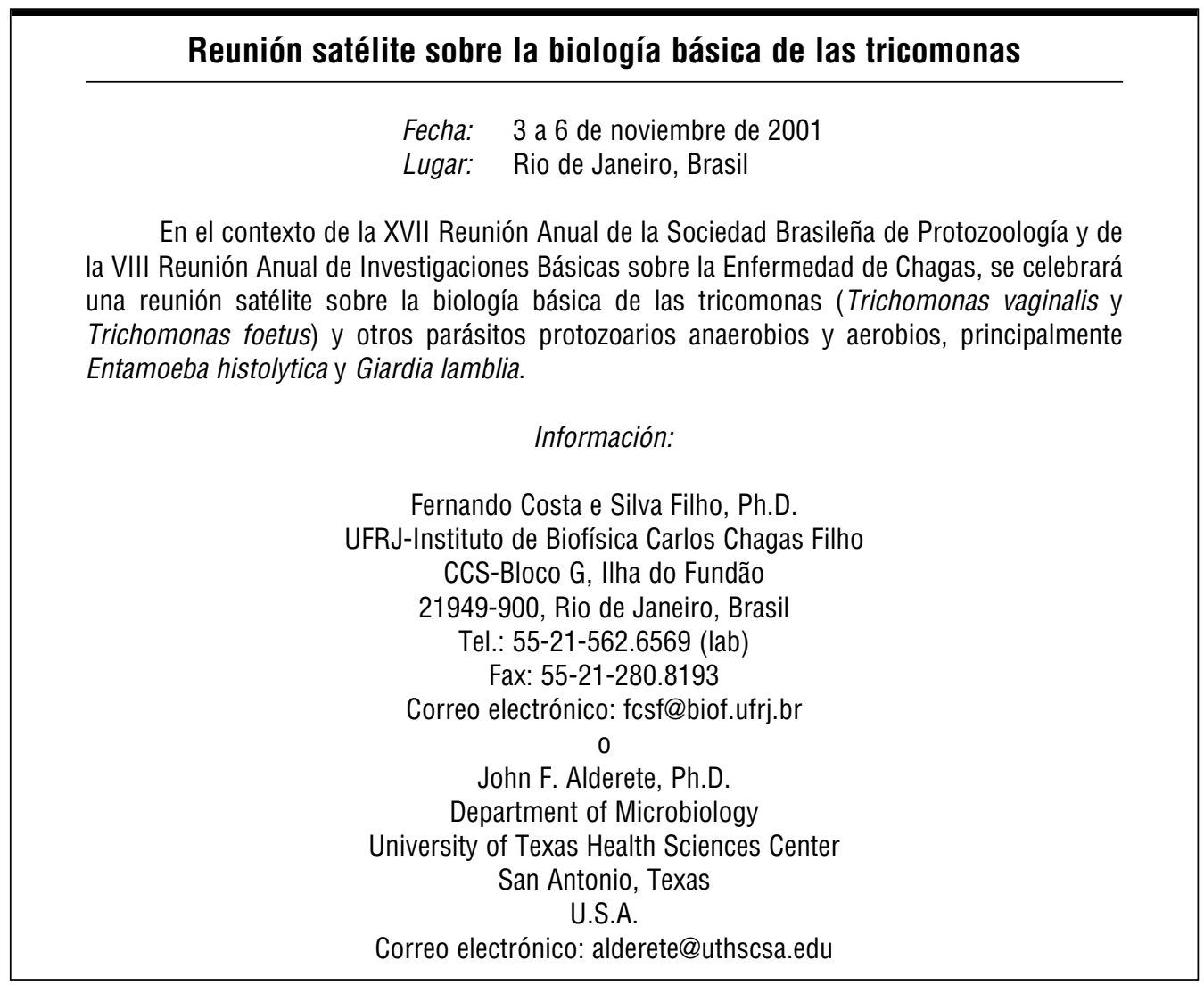

